\title{
“EU SOU DE TODOS OS LUGARES": MIGRANTES CARIBENHAS NA FRONTEIRA FRANCO-BRASILEIRA
}

\begin{abstract}
RESUMO: O objetivo deste artigo é destacar a origem de duas mulheres, o Caribe, e como a mobilidade enquanto elemento constitutivo da história dessa região reflete-se nas experiências dessas mulheres migrantes em suas vivências no estado do Amapá e na fronteira franco-brasileira. Michelle e Samantha, naturais de Guadalupe, departamento ultramarino francês, respaldam a ideia de que os motivos que levam a maior parte dos moradores de países caribenhos a deixar seus países estão ligados a uma familiaridade com a mobilidade no espaço que os faz afrontar mais facilmente as dificuldades inerentes à experiência migratória. Considerando as múltiplas perspectivas sobre a fronteira, este estudo considera também as fronteiras simbólicas de gênero, raça e classe nas trajetórias pessoais de duas migrantes caribenhas. A partir de entrevistas semiestruturadas, realizadas nas cidades de Macapá e Oiapoque, foi possível relacionar as histórias das duas migrantes, e discutir sobre diáspora caribenha (HALL, 2003), crioulidade (GLISSANT, 1981), transnacionalidade (SCHNAPPER, 2001) e pertencimento (OLWIG, 2007).
\end{abstract}

Palavras-chave: Mulheres; Migração; Caribe; Fronteira.

\section{"I AM FROM EVERYWHERE": CARIBBEAN MIGRANTS ON THE FRANCO-BRAZILIAN FRONTIER}

\begin{abstract}
The purpose of this article is to highlight the origin of two women, the Caribbean, and how mobility as a constitutive element of the history of this region is reflected in the experiences of these migrant women in their experiences in the state of Amapá and on the Franco-Brazilian border. Michelle and Samantha, natives of Guadalupe, French overseas department, support the idea that the reasons that lead most Caribbean residents to leave their countries are linked to a familiarity with mobility in space that makes them more easily face difficulties inherent to the migratory experience. Considering the multiple perspectives on the border, this study also considers the symbolic borders of gender, race and class in the personal trajectories of two Caribbean migrants. From semi-structured interviews, conducted in the cities of Macapá and Oiapoque, it was possible to relate the stories of the two migrants, and discuss Caribbean diaspora (HALL, 2003), creolity (GLISSANT, 1981), transnationality (SCHNAPPER, 2001) and belonging (OLWIG, 2007).
\end{abstract}

Keywords: Women; Migration; Caribbean; Border.

\section{INTRODUÇÃO}

\footnotetext{
${ }^{1}$ Mestra em Estudos de Fronteira pela Universidade Federal do Amapá (PPGEF/UNIFAP). Professora substituta no curso de Letras da Universidade do Estado do Amapá (UEAP). E-mail: liviaverenac@gmail.com
} 
A feminização da migração trata não só do crescimento da quantidade de mulheres migrando, mas principalmente da diversificação das estratégias de mobilidade feminina. Mulheres em movimento estabelecem diversas formas de pertencimento e através de seus processos migratórios tornam-se agentes de mudança no país de residência e de origem, por outro lado, enfrentam, também, novos problemas familiares, identitários, intergeracionais, de saúde, discriminação e violência.

Considerando a tendência da feminização dos fluxos migratórios, esta pesquisa considera as articulações das categorias raça, gênero, classe e nacionalidade com base nas trajetórias de vida de duas mulheres migrantes no Amapá, contribuindo para capturar as consequências estruturais e dinâmicas da feminização da migração na fronteira entre o estado do Amapá e a Guiana Francesa (Departamento Ultramarino Francês), além de proporcionar reconhecimento e protagonismo a esses sujeitos historicamente marginalizados nos estudos migratórios.

$\mathrm{O}$ artigo está dividido em três partes. Na primeira seção são evidenciadas as características da diáspora caribenha; na segunda seção, é apresentada a professora Michele, que vive em Macapá e a questão da crioulização em sua perspectiva; na terceira parte do trabalho, o foco é a trajetória da professora Samantha, que na época da entrevista morava na cidade Oiapoque, na fronteira com a cidade Saint-Georges, na Guiana Francesa, nesta última seção é analisado o papel da fronteira nas noções de pertencimento e transnacionalidade.

\section{DIÁSPORA CARIBENHA: NEGOCIANDO IDENTIDADES}

“A migração tem sido um tema constante na história do Caribe", afirma Stuart Hall (2003) em Pensando a diáspora: reflexões sobre a terra no exterior. Foi a partir da experiência caribenha que o autor teorizou sobre Estudos Culturais, Identidade e Diáspora. Hall, caribenho da Jamaica, migrou para a Inglaterra aos dezenove anos e lá viveu até sua morte. Esse deslocamento constituiu o que Stuart Hall denominou de experiência desenraizadora, sentimento que muito frequentemente acompanha os 
migrantes em sua vivência diaspórica: distanciamento e estranhamento em relação aos dois espaços (a nação de origem e a nação de residência):

Conheço intimamente os dois lugares, mas não pertenço completamente a nenhum deles. E esta é exatamente a experiência diaspórica, longe o suficiente para experimentar o sentimento de exílio e perda, perto o suficiente para entender o enigma de uma 'chegada' sempre adiada. (HALL, 2013, p. 410).

O conceito clássico de diáspora está atrelado à ideia de dispersão de povos por motivos políticos ou religiosos, em virtude da perseguição de grupos dominadores e intolerantes. Indivíduos pertencentes a períodos históricos diferenciados presenciaram situações de diáspora. É o caso do movimento dos judeus ao longo de vários séculos na história do mundo. Contudo, a virada dos anos 2000, inaugura o momento corrente em que o conceito de diáspora passa por um momento de revisão e consolidação (SCHNAPPER, 2001). Por isso, é importante considerar a constante mutação das acepções de diáspora, tendo em vista a constância da reformulação dos aspectos da dispersão de pessoas pelo mundo.

Os processos diaspóricos apresentam conexões e semelhanças entre eles, além do mais, a situação dos migrantes intervém na formação da identidade cultural e na organização social pós diáspora. Além do mais, o sujeito diaspórico, o sujeito híbrido, não se refere a uma composição racial mista da população, mas a um processo de tradução cultural que nunca se completa, uma vez que está em constante negociação, perturbando modelos fixos de identidade cultural. De acordo com Khachig Tölölyan (2011), atualmente o termo diáspora é apenas um dos utilizados para designar as várias formas de dispersão e mobilidade de sujeitos e comunidades entre territórios:

Outras formas de mobilidade e dispersão incluem a migração na intenção de conseguir educação, empregos, terra, acomodação, nova cidadania ou uma combinação destes; há ainda comerciantes móveis e trabalhadores itinerantes que circulam entre a pátria e oportunidades extraterritoriais; há as vítimas de deportação em massa, refugiados e quem procure asilo - alguns escolhem a mobilidade, outros a têm imposta a si; alguns são arrancados, outros se arrancam a si mesmos. Alguns eventualmente voltam para casa, muitos são assimilados, e o restante pode se consolidar nas comunidades diaspóricas. (TOLOLYAN, 2011, p. 44). 
Mesmo que a identidade esteja ligada ao nascimento e ao parentesco; é necessário adotar a consideração de que qualquer forma de dispersão abala a origem reconhecível do sujeito, cujo deslocamento permeia a sensação de desconforto e possibilitará a impuridade, a amalgamação e variações novas. É desse aparato teórico que Hall (2003) se utiliza para explicar a diáspora e a sincretização da identidade cultural caribenha. $\mathrm{O}$ autor assinala que a condição dispersa e fragmentada do migrante se torna, na pósmodernidade, a condição mais estabilizadora na experiência contemporânea. A fragmentação, o entre lugar, passa a ser como estar em casa.

O sentimento de pertencer é algo móvel, não estanque, construído, segundo Benedict Anderson (2003), a partir de um "sujeito imaginado", que por sua vez faz parte de uma "comunidade imaginada", que está sempre em jogo. Ademais, a diáspora implica na construção da identidade cultural, pois as "identidades tornam-se múltiplas" (HALL, 2003) na medida em que uma série de identificações e reidentificações criam um panorama de identidades caribenhas mutantes, ainda que resistentes.

Sendo assim, Hall (2003) percebe a diáspora como elemento constitutivo da história caribenha, marcada "por uma concepção identitária que vive pela e não a despeito da diferença, e fundamentalmente pelo hibridismo" (HALL, 2003, p. 197). As questões levantadas pelo autor jamaicano: estranhamento, hibridização, entre lugar, atravessam, neste trabalho, as experiências de duas mulheres, caribenhas como ele, que migraram para o extremo norte do Brasil: Michelle e Samantha.

Michelle, através da migração permanente, naturalizada e vivendo há 18 anos em Macapá, não conheceu Samantha, que através da migração temporária, de 1 ano, morou em Macapá e Oiapoque, porém os caminhos de ambas possuem pontos em comum: elas são naturais de Guadalupe, viveram na Guiana Francesa e na França, possuem alta escolaridade, chegaram ao Brasil pelo Amapá, atualmente são professoras de língua francesa e estão na mesma faixa etária.

\section{MICHELE: DE GUADALUPE AO BRASIL}

Em 2000, Michelle, natural de Guadalupe (ver Mapa 01) estava de volta à sua terra natal, após concluir a Escola Politécnica, em Paris. Guadalupe é um departamento ultramarino da República Francesa no Caribe, portanto, Michelle é cidadã francesa, o que, 
aliado ao fato de já possuir uma irmã morando em Paris, propiciou que ela estudasse na Europa. Michelle saiu de Guadalupe para estudar em Paris já adulta, mas desde cedo pensava em partir: "Eu queria ver outras coisas". A França é tradicionalmente o destino principal dos guadalupenses e, no caso de Michelle, a irmã que até hoje vive em Paris exemplifica a migração como elemento constitutivo das relações familiares, já que é rara a família caribenha que não tenha alguém que esteja no exterior.

Após concluir seus estudos na França, Michelle conseguiu um emprego em Caiena, na Guiana Francesa, e foi lá que recebeu o convite de uma amiga macapaense para conhecer o Amapá. Sem nunca ter estado no Brasil, Michelle aceitou o convite da amiga e acabou retornando mais duas vezes, até que resolveu ficar. Brasil, Amazônia, Amapá não faziam parte dos seus planos: “O Brasil era um país longe. Se ouvia pouco falar do Brasil. Nem de longe me passava na cabeça um dia falar português. Brasil foi um acaso total”. Michelle reside há 17 anos em Macapá, trabalha como professora universitária e naturalizou-se brasileira.

Alta escolarização e motivação de ordem não-econômica são aspectos que caracterizam fluxos migratórios contemporâneos de mulheres, demonstrando a necessidade de se lançar um olhar para as migrações que não apenas ressalte a sua participação, mas que contemple a perspectiva de gênero. Nos fluxos contemporâneos, as mulheres tendem a migrar sozinhas, quebrando a imagem daquelas que esperam, ou que seguem os passos dos homens. É o caso de Michelle que já havia experimentado a vida fora de sua terra natal e queria fazê-lo novamente, encontrando na repentina oportunidade de vir para o Amapá uma nova chance de sair de sua ilha. Já morando em Macapá, Michelle ainda retornou à França para cursar um mestrado, o que contribuiu na sua carreira acadêmica no Brasil. Michelle visita Guadalupe todos os anos e futuramente pretende voltar. Aqueles que passam pela diáspora mantém consigo o desejo do retorno, da volta ao local do nascimento. Muitos conseguem esse feito, outros constroem a vida mantendo essa esperança. De fato, parece que uma das implicações da diáspora está, além da hibridização cultural pelo efeito da zona de contato (BHABHA, 2013), no desejo de querer regressar ao ponto zero, por um processo consciente ou inconsciente. Michelle deseja retornar, mas também já criou raízes no Amapá: “Gostaria de voltar, não sei se ia passar seis meses para lá, seis meses para cá, seria o ideal”. 
A intersecção cultural e identitária provocada no plano físico-geográfico pela diáspora, pela dispersão dos povos que saem de sua terra natal e passam a viver em outra, não faz com que haja o abandono das origens. A origem se mantém, mas também se mistura na nova situação de vida apresentada, sendo também modelada pelo desejo de um dia retornar ao seu lugar de nascimento. No caso de Michelle, que pode visitar anualmente Guadalupe, esse retorno envolve um novo olhar sobre a terra natal, aguçado pela vivência no exterior: "É aquela coisa, você achava que a sua casa não era boa o suficiente, só quando você viaja você começa a dar valor".

Stuart Hall (1997) frisa as trocas de experiências como necessidade de negociação social para o migrante, pois, as pessoas em mobilidade necessitam negociar com as novas culturas em que vivem, "sem simplesmente serem assimiladas por elas e perder completamente a sua identidade, devem aprender a habitar no mínimo duas identidades " (HALL, 1997, p. 05). Assim, migrar comporta sempre uma experiência de redefinição identitária, Michelle exemplifica ao pontuar que: “O problema de identidade a gente sente quando sai".

A identidade mencionada por Michelle é a negritude, em sua trajetória pessoal é notório como ser negra no Brasil tem sido tão ou mais impactante do que ser propriamente estrangeira. Michelle pode "passar" por brasileira em diversas situações, mas o fato de ser negra em um país onde a questão racial "é totalmente diferente" do que ocorre em Guadalupe, provocou-lhe novas reflexões, já que "Vindo [para o Brasil], eu não sabia que existia esse problema tão grave aqui [racismo], não imaginava”. (Michelle, Macapá, janeiro de 2018).

Dessa forma, Michelle passa pelas mesmas situações de micro racismos que uma mulher negra brasileira. O termo micro racismo é uma adaptação de micromachismos (BONINO, 1998), esse último corresponde ao machismo que persiste ao longo do tempo, não é agressivo ou premeditado e é uma consequência da internalização de preconceitos, comportamentos sexistas e sociais, assim, os micro racismos são os comportamentos, comentários e uma série de gestos nas relações cotidianas carregados de estereótipos raciais em detrimento das minorias étnicas.

Há no Brasil um imaginário de que existem trabalhos para negros e outros para brancos, entrar em uma loja e perguntar a uma pessoa negra o preço de um produto, associar pessoas negras a trabalhos precarizados, por exemplo, é uma configuração 
resultante do racismo. Michelle levou um casal de amigos paulistas para conhecer Guadalupe. Os amigos brancos e de classe média, "não estavam acostumados a ver negros em determinados lugares. De alguma maneira ficaram surpresos. Isso teve um impacto neles. O negro que eles veem aqui é da favela. Lá viram negros com mais dinheiro que eles”. (Michelle, Macapá, janeiro de 2018).

\section{CRIOULIZAÇÃO CARIBENHA: "UMA JUNÇÃO DE VÁRIAS COISAS"}

Ainda se mantêm como Départaments d'Outre-Mer (DOM) da França, as Ilhas de Guadalupe, São Martinho, São Bartolomeu e Martinica, nas Antilhas; e a Guiana Francesa, na América do Sul. Guadalupe e Martinica foram colônias francesas de 1635 a 1946, tendo recebido mão de obra escrava para o trabalho de produção de mercadorias tropicais como cana de açúcar, rum, cacau, café e frutas, principalmente a banana. Em 1946, as ilhas se tornam departamentos ultramarinos franceses, conquistam alguma autonomia, mas permanecem territórios franceses regidos pelas leis da antiga metrópole.

Durante o processo de colonização, o termo crioulo passou a fazer menção às novas línguas surgidas do convívio entre senhores e escravos, a língua intermediária usada no dia-a-dia da lavoura e da casa grande. O termo crioulo designava alguém que é do país, logo uma criança branca nascida nas colônias europeias era chamada de crioulo independente de sua etnia. Só depois é que seu emprego foi usado para designar a população negra, estendendo-se aos animais, objetos e consequentemente à língua desta população, o Crioulo: "Você nasce, teus pais falam crioulo contigo, teus tios falam crioulo, você fala crioulo, aí você é escolarizado na língua francesa" (Michelle, Macapá, janeiro de 2018).

No processo pós-abolição da escravidão nos departamentos ultramarinos, as escolas abriram suas portas para os filhos dos ex-escravos, mas nestas instituições o crioulo não era aceito e a língua francesa prevalecia, isto é, para conseguir uma colocação digna na sociedade, era preciso falar francês:

o negro tentará falar francês porque o crioulo, apesar de ser sua língua materna, língua das canções de ninar e dos contos ouvidos à noite, nas festas e nos velórios, é considerado como um patois, um dialeto que se ama e se despreza ao mesmo tempo. (FIGUEIREDO, 1998, p. 20). 
A própria diversidade das línguas crioulas, constituídas a partir da base espanhola, portuguesa, inglesa e francesa está intimamente relacionada ao processo sócio histórico e político do Caribe. A realidade caribenha tem no crioulo elemento central da identidade cultural, evidenciando o diálogo entre o mundo europeu da escrita, da alfabetização e das tradições literárias, por um lado e o mundo da oralidade, do crioulo, do contador de histórias e das festas populares, por outro lado:

Falar crioulo, em outras palavras, consiste em exercer plenamente os encontros que forjam o mosaico identitário das Américas, espaço marcado pela alteridade, pela mestiçagem e pelo encontro dos mais diversos elementos culturais que se crioulizam para compor algo "absolutamente imprevisível, absolutamente novo que é a realidade crioula” (GLISSANT, 1997, p. 15).

Professora de língua francesa, Michelle já ouviu comentários entre os alunos como: "Mas, em Guadalupe não falam francês", com a intenção de alegar que por ter como língua materna o crioulo e não o francês, Michelle estivesse menos apta para ensinar a língua francesa. Pensamentos que entrecruzam vários preconceitos, como o linguístico, que assim é contestado por Michelle:

Eu pergunto: "Por que não falam francês? Por que os guadalupenses não são brancos? "A língua francesa não é minha língua materna mas para alguém que fala só uma língua que sempre aprendeu só uma língua, como o brasileiro, é muito complicado entender isso. Quando você é bilíngue, crioulo-francês, você passa de uma língua para outra facilmente. Alguém de fora que ouve, pergunta: eles não estão falando francês? O que eles estão falando? (Michelle, Macapá, janeiro de 2018).

Portanto, mesmo dominando tanto a língua crioula quanto a língua francesa e com formação acadêmica no ensino de língua francesa, Michelle, de certa forma, no início de seu trabalho como professora no Amapá, passou pelo questionamento dos discentes em relação ao seu domínio do idioma, já que supostamente não estaria ensinando a língua francesa falada no continente europeu, pois sendo caribenha, também maneja a língua crioula. Fato é que as dúvidas dos alunos foram dissipadas conforme Michelle seguiu de maneira exitosa e reconhecida na Academia, no entanto, os questionamentos dos discentes revelam um pensamento muito comum demonstrando como a ideia sobre as variantes linguísticas também sofre resquícios da colonização. 
Em Pele negra, máscaras brancas (2008), no capítulo “O negro e a linguagem”, Frantz Fanon considera que o negro se situa de modo característico diante da linguagem europeia. $\mathrm{O}$ autor martinicano reflete a relação dos antilhanos e africanos com a língua francesa, que por muito tempo atribuíram ao crioulo e nas variantes do francês o status de "dialeto" e não de língua. Fanon observa então que o negro antilhano será tanto mais branco, isto é, se aproximará mais do homem verdadeiro, na medida em que adotar a língua francesa.

Todo povo colonizado - isto é, todo povo no seio do qual nasceu um complexo de inferioridade devido ao sepultamento de sua originalidade cultural — toma posição diante da linguagem da nação civilizadora, isto é, da cultura metropolitana. Quanto mais assimilar os valores culturais da metrópole, mais o colonizado escapará da sua selva. Quanto mais ele rejeitar sua negridão, seu mato, mais branco será. (FANON, 2008, p. 34).

Dessa forma, o pensamento dos alunos que acreditavam que a professora guadalupense poderia ensiná-los o francês do Caribe e não francês europeu reflete a colonialidade do pensamento abordada por Fanon (2008), que contesta o "complexo de inferioridade" em considerar a língua francesa, e a França/Europa superiores em relação às línguas crioulas/caribenhas/América. Para Fanon (2008, p. 13), "falar é existir completamente para o outro" e entre os mecanismos da colonização, o Negro é "dito" e assim alienado, mas, mesmo quando ele toma a palavra, não o pode fazer sem a língua do Outro, o francês, língua do Branco.

Aproximando-se das deias de Fanon sobre a alienação do negro antilhano, uma nova geração de escritores passou a refletir sobre o conceito de crioulidade, pensando o Caribe através da intersecção de múltiplas heranças culturais. O manifesto Elogio da Crioulidade, publicado em 1989 pelo linguista Jean Bernabé e pelos escritores Patrick Chamoiseau e Raphaël Confiant, tornou-se um marco nos debates acerca da diglossia linguística nas ilhas francesas no 47 Caribe; a diglossia refere-se à situação linguística em que duas línguas coexistem, sendo que o uso de uma está sujeito à condição comunicativa da outra, adicionada ao valor de hierarquia e dominação:

Nem europeus, nem africanos, nem asiáticos, nós nos proclamamos crioulos. Declaramos que a Crioulidade é o cimento da nossa cultura e deve reger as fundações da nossa antilhanidade. A Crioulidade é a interação de elementos caribenhos, europeus, africanos, asiáticos que o jugo da história reuniu no mesmo solo. (BERNABÉ, CHAMOISEAU, CONFIANT, 2015, p.26-27). 
Ao investigar a questão identitária antilhana, em Le Discours Antillais (1981), o autor martinicano Edouard Glissant defende que as Antilhas representam a “crioulização", compreendida como a hibridização de elementos culturais, étnicos e linguísticos entre as coletividades: "Eu nomeio crioulização o encontro, a interferência, o choque, as harmonias e as desarmonias entre as culturas, na totalidade realizada do mundo-terra. Minha proposição é que hoje o mundo inteiro se criouliza e arquipeliza”. (GLISSANT, 1997, p. 194) A alegoria de "pensamento-arquipélago" seria a oposição ao "pensamento continental", hegemônico e universalista. Essa ideia converge com o processo de negociação de identidades que caracteriza o sujeito pós-moderno, apontado por Hall (2005), além da reafirmação da crioulização por Michelle:

\begin{abstract}
Eu sou crioula, e esse termo não é muito bem aceito aqui. Inclusive falamos em brancos crioulos. Crioulo é essa junção de várias coisas. Eu não sou nem europeu, nem africano, nem indígena, nem asiático, eu sou a mistura de tudo isso. Eu existo, então não tentem me colocar só aqui, ou só ali, eu estou no meio de vocês, eu existo. Não estou dizendo que eu não sou negra, eu sou negra, mas dentro de mim, culturalmente, eu tenho outras coisas e eu não posso negar tudo isso; meu corpo não deixa, minha mente não deixa. Morando no Brasil, eu sou um pouco brasileira. (Michelle, Macapá, janeiro de 2018).
\end{abstract}

A trajetória de Michelle demonstra o pertencimento a múltiplas identidades nacionais, sociais, culturais, linguísticas e étnicorraciais. A professora é francesa de Guadalupe, mas também se sente brasileira; tem o crioulo como língua materna, o francês como segunda língua, o português como terceira, além de ensinar a língua francesa para falantes de português; em sua terra natal definia-se como crioula, no Brasil é chamada de mulata, morena, negra.

Desde que saiu de Guadalupe para estudar na Guiana Francesa, Michelle está em constante mobilidade, ainda que resida em Macapá, e anualmente retorne à sua terra natal. Em 2018, por exemplo, esteve também no Canadá para um curso de aperfeiçoamento para professores de língua francesa, seu trabalho como professora de língua estrangeira em uma Universidade Federal, respaldado por uma condição financeira favorável, são fatores que impulsionam essa circulação. Michelle, ao dizer "Eu existo, então não tentem me colocar só aqui, ou só ali, eu estou no meio de vocês, eu existo" exemplifica o "Eu" relacional e móvel apontado por Bauman (2001) e Hall (2005), como aquele cujo 
processo de identificação ocorre em meio à complexidade e à diversidade de possibilidades de escolha. Ao afirmar ser “a junção de várias coisas”, Michelle exalta um discurso em que a diversidade cultural é percebida no processo de descolonização ou de pós-colonização (BHABHA, 2003), considerando a sua característica transnacional e transcultural. Francesa de Ultramar, Michelle reforça que não é "europeia, nem africana, nem indígena, nem asiática, é a mistura de tudo isso", sintetizando assim a ideia de desconstrução de binarismos e metanarrativas do discurso colonial. Autores como Quijano (2014), Memmi (2007), Fanon (2008) defendem esse confronto das relações transversais que se estabelecem no universo colonial na ressignificação das categorias de colonizador/colonizado.

Ao orgulhar-se de ser crioula, Michelle manifesta a desalienação intelectual almejada por Fanon (2008), e ao declarar "Eu existo" simboliza o ser, quando a colonização relegou o negro à zona do "não-ser", pois o que o autor martinicano chamou de "epidermização do racismo", introjetou no negro um complexo de inferioridade que o fazia buscar falar, pensar e agir como branco. Conterrânea de Michelle, Samantha também manifesta essa consciência e orgulho de ser crioula e de "ser de todos os lugares", como será mostrado no item a seguir.

\section{SAMANTHA: MUITAS FORMAS DE SER FRANCESA}

Assim como Michelle, Samantha nasceu em Guadalupe, contudo, seu caminho até chegar ao Amapá foi mais longo. Samantha morou nove meses em Macapá e nove meses em Oiapoque, entre 2016 e 2018, lecionando língua francesa nos respectivos campi dos IFAP (Instituto Federal do Amapá). A entrevista com Samantha ocorreu em maio de 2018, em Oiapoque, onde ela findava sua estadia no Brasil e preparava-se para retornar a Paris, onde morava há dez anos. Aos 40 anos, Samantha já morou em Guadalupe, na Guiana Francesa, em Portugal e na França.

A mãe de Samantha saiu de Guadalupe adolescente para estudar em Paris, retornou anos mais tarde a Guadalupe para ter sua primeira filha, Samantha, em sua terra natal. Os pais de Samantha, ambos guadalupenses, mudaram-se para Paris quando ela tinha apenas um ano de idade; ao completar sete anos, sua família retornou a Guadalupe já com uma segunda filha nascida na França, a terceira filha do casal nasceu em Guadalupe. Assim, Samantha permaneceu 
em Guadalupe dos sete aos dezoito anos, quando a família se mudou para Guiana Francesa, em 1998, onde ela cursou o ensino superior em Licenciatura em Língua, Literatura e Civilização Lusófona; em 2002, ela estudou um semestre da graduação em Portugal e em 2004 partiu para França para cursar o mestrado na sua área de atuação.

Diante desse quadro de constante mobilidade, Samantha, "joga com suas identidades" ao explicar sua origem e pertencimento. Identifica-se como francesa, porém, estando no Amapá, onde "sendo negra e francesa já pensam que você é da Guiana”, ela precisou reaver sua identidade:

Eu sou francesa. Na verdade, eu me senti francesa por muito tempo, mas hoje eu já me sinto mais internacional, eu sou de todos os lugares, mas eu falo primeiro que eu sou francesa, mas aí perguntam francesa de onde? Aqui no Amapá as pessoas têm esse hábito de me etiquetar de guianense, então eu sempre tenho que dizer, "Mas não sou da Guiana, eu sou francesa, mas de Guadalupe". Eu sempre tenho que reivindicar o meu lado guadalupense para as pessoas daqui. (Samantha, Oiapoque, maio de 2018).

A identidade é construída a partir das relações sociais e se inscrevem tanto nos sujeitos sociais quanto do ponto de vista dos grupos e dos próprios sujeitos constituintes destes grupos. No caso de Samantha, ela utiliza o que Cuche (2012) chama de "estratégia de identidade", isto é, busca a autoafirmação perante determinado grupo de indivíduos, para este autor, a identidade serve para que nos localizemos como indivíduo e localizemos pessoas ou grupos simbólicos ao nosso padrão, motivo pelo qual a identidade só pode ser entendida num contexto relacional.

Em Grupos étnicos e suas fronteiras, Barth (2011) explora o conceito de etnicidade, segundo o qual os atores sociais identificam-se e são identificados pelos outros através da dicotomização Nós/Eles, estabelecida a partir de traços culturais que se supõe derivados de uma origem comum e realçados nas interações raciais. Segundo Samantha, alguns amapaenses com quem conviveu a identificavam como guianense, com base na cor de sua pele, de seu sotaque francês e pela proximidade geográfica do estado com a Guiana Francesa.

Tanto em Cuche (2012), quanto em Barth (2011), a identidade é compreendida em um contexto relacional, quando indivíduos de culturas diferentes interagem, esta 
relação surge por meios de processo de rotulação mútua, no decurso dos quais os grupos atribuem-se e impõem-se aos outros nomes étnicos.

"A existência e a realidade de um grupo étnico não podem ser atestadas por outra coisa senão pelo fato de que ele próprio se designa e é designado por seus vizinhos" (BARTH, 2011, p. 186). Dessa maneira, a dicotomização entre Nós (amapaenses) e o outro (Samantha) caracteriza uma atribuição categorial equivocada, de guianense, e tem como efeito o resgate por parte de Samantha das fronteiras que a identificam como guadalupense.

Samantha nasceu em um DOM (departamento de ultramar) logo, é francesa, mas diante do fato da França manter vários territórios além da Europa, é pertinente a pergunta: francesa de onde? Pessoas como Samantha, nascidas em departamentos ultramarinos franceses - espalhados pela América, África, Oceania e Antártica - mesmo antes de residirem no exterior, possuem essa característica peculiar relativa à cidadania francesa. Os habitantes dos departamentos ultramarinos franceses na América: Guiana Francesa, São Pedro e Miquelão, São Martinho e São Bartolomeu, Guadalupe e Martinica são cidadãos franceses mesmo que nunca tenham pisado no que chamam de França hexagonal, o território francês na Europa, mas em geral é a Metrópole, ou França Continental, o destino mais comum daqueles que partem das Antilhas Francesas.

\section{A FRONTEIRA FRANCO-BRASILEIRA COMO OPÇÃO: TRANSNACIONALIDADE E PERTENCIMENTO}

Samantha cursou a faculdade de Licenciatura em Língua, Literatura e Civilização Lusófona na Guiana Francesa, e durante esse período pôde cruzar a fronteira francobrasileira e conhecer a cidade brasileira de Oiapoque. Por isso, diferente de Michelle que aprendeu português após mudar-se para o Amapá, Samantha estudou o idioma na Academia e aperfeiçoou o conhecimento ao cursar uma Especialização em Portugal, depois mudou-se para Paris.

Após oito anos vivendo em Paris, Samantha recebeu o convite do Programa Leitores Franceses, parceria entre a Embaixada da França no Brasil e o Conselho Nacional das Instituições Federais de Educação Profissional, Científica e Tecnológica (CONIF), que estava recrutando professores nativos, coincidindo com o desejo antigo dela de visitar o Brasil para imersão 
cultural, pois estava há anos sem praticar a língua portuguesa.

Ao aceitar lecionar língua francesa no Brasil, Samantha poderia optar para qual estado gostaria de ir, pois o Programa Leitores Franceses ocorre nos Institutos Federais espalhados pelo país. Ao descartar o sul e sudeste do Brasil para trabalhar no Programa Leitores Franceses, Samantha deliberou que não queria mudar-se para uma região semelhante a Paris: invernos rigorosos, constante e intensa movimentação:

Em Paris eu tinha uma vida corrida, correr para pegar o ônibus, correr para pegar o trem, demorava para fazer tudo, uma vida estressada e no sul ia ser a mesma coisa, transporte público, essas coisas. No Rio, tem a violência, não vou para o Brasil para ter uma vida fechada, com medo, não quero viver com medo de receber uma bala perdida. (Samantha, Oiapoque, maio de 2018).

Portanto, não foi o acaso que trouxe Samantha, ela literalmente olhou o mapa do Brasil e elegeu o estado do Amapá, porém, ao elencar as razões, destaca como a fronteira franco-brasileira (Ver Mapa 01) foi preponderante nessa escolha:

O Amapá tem um laço muito estreito com a Guiana, que é o país do meu coração, hoje quase me sinto mais guianense, é onde eu também gostaria de morar. França, Guadalupe ou Guiana, eu escolheria Guiana, sem duvidar, por isso também escolhi o Amapá, faz fronteira com a Guiana, dá pra viajar pra lá e voltar. Então eu escolhi o Amapá mesmo pela fronteira com a Guiana. Por exemplo, deu pra passar as férias de Natal lá, já que eu sabia que não daria para ir à França. Natal é festa de família, não imagino passar o natal longe das pessoas que eu amo. (Samantha, Oiapoque, maio de 2018).

Mapa 02. Fronteira entre Amapá e Guiana Francesa 
Filosofia

Alamedas

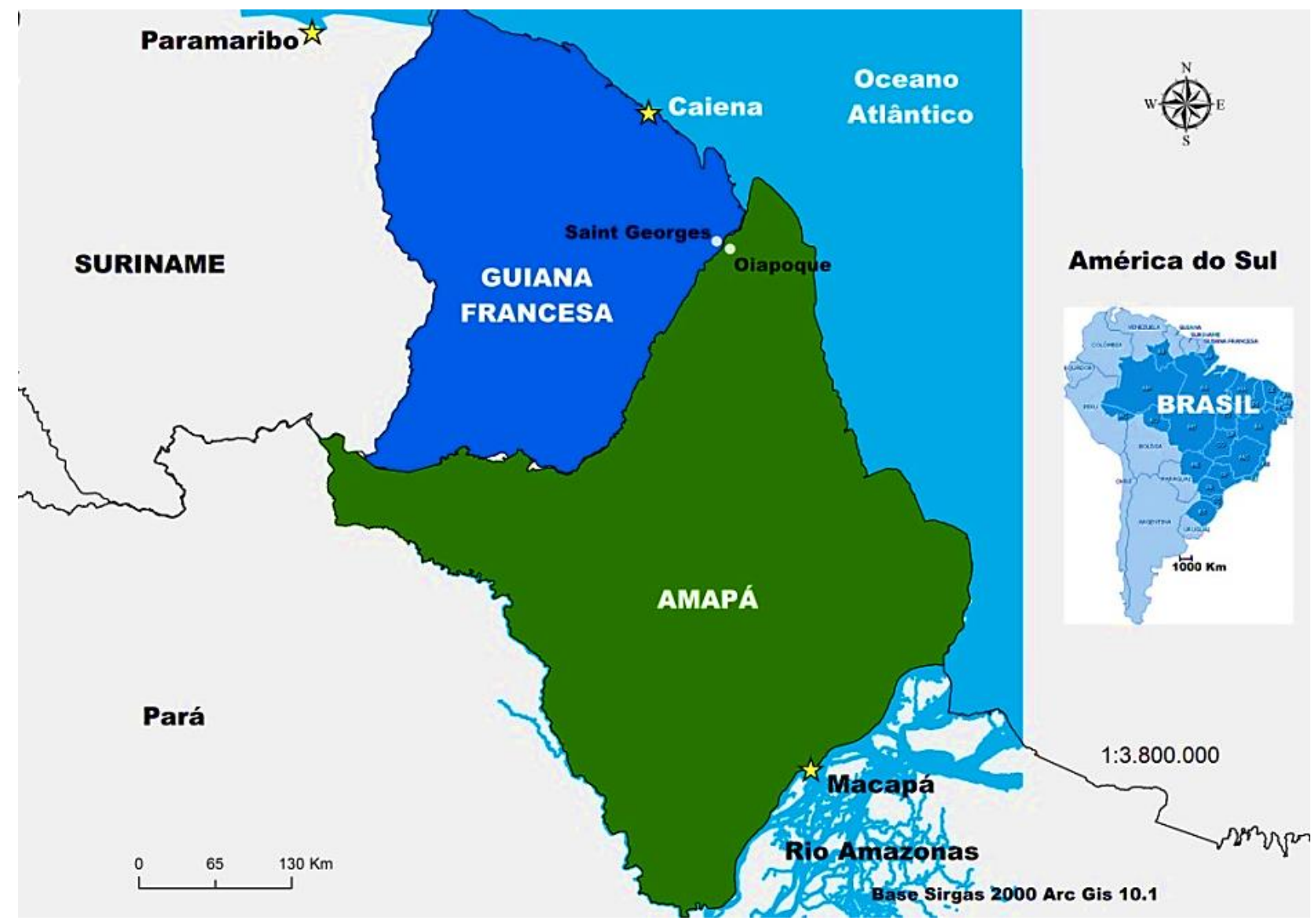

Fonte: Base Cartográfica Sirgas, 2017.

Apesar da forte relação afetiva também com a França, onde residiu por mais de dez anos, o retorno almejado por Samantha não está vinculado a Guadalupe, onde nasceu e onde possui muitos familiares, mas à Guiana Francesa, onde viveu parte da infância e adolescência e onde vivem seus pais, uma de suas irmãs e sobrinhos, a outra irmã ainda vive em Paris. Assim, a família de Samantha tem um caráter transnacional, o qual desestrutura as acepções de família que associam a co-residência e a presença como elementos fundamentais para sua compreensão, já que as relações que se constroem entre seus membros transcendem a espacialidade e as fronteiras físicas, gerando novas modalidades de cuidado e diferentes formas de relações pessoais e pertencimento. Cabe ressaltar que nem todos os migrantes e seus descendentes desenvolvem práticas sociais de caráter transnacional:

Definimos o transnacionalismo como os processos pelos quais imigrantes constroem campos sociais que conectam seu país de origem-gene e seu país de assentamento. Os imigrantes que constroem campos e sociais são designados 


\begin{abstract}
"transmigrantes". Transmigrantes desenvolvem e mantém relacionamentos múltiplos - familiar, econômico, social, organizacional, religioso, política - que vai além das fronteiras. Os transmigrantes agem, tomam decisões e se sentem envolvidos, eles desenvolvem identidades dentro de redes sociais que os conectam a duas ou mais sociedades simultaneamente. (GLICK - SCHILLER, BACH, SZANTON- BLANC, 1992, p. 04).
\end{abstract}

Ao argumentar sobre as condições de transnacionalidade, Bryceson e Vuorella (2002) sugerem que o pertencimento a uma família é semelhante ao pertencimento a uma nacionalidade, no sentido de que ambos são como "comunidades imaginadas", realizadas no estabelecimento de algumas fronteiras e condicionalidades (vistos), além do mais, essas famílias geralmente possuem um histórico migratório que facilita a continuidade das relações à distância.

Nessa perspectiva, o parentesco afeta e é afetado nos sistemas migratórios. Para a antropóloga Janet Carsten (2000), em Culture of Relatedeness, a ideia de parentesco pode também ser construída e não apenas reflexo das lógicas biológicas, isto é, fenômenos como a adoção transnacional, o casamento homoafetivo, o poliamor, relações de amizade, e muitos outros passam a ter uma dimensão relativa ao que tradicionalmente chamamos de parentesco.

$\mathrm{O}$ conceito de relatedeness (conectividade ou relacionalidade) discutido por Carsten (2000) é utilizado também pela antropóloga dinamarquesa Karen Olwig ao tratar das relações entre parentesco, migração e espaço no Caribe. Particularmente em Caribbean Journeys: An Ethnography of Migration and Home in Three Family Network, Olwig (2007) analisa três redes familiares marcadas pela migração, visto que essa população foi historicamente forçada a delinear novos padrões de vida, sendo em sua maior parte migrante ou descendente de migrante e vivendo, frequentemente, em um ambiente estrangeiro, por isso:

A raça é apenas uma faceta no complexo de fatores econômicos, de classe, de gênero e étnicos que moldam as experiências migratórias no Caribe. A interpretação desse complexo em qualquer contexto depende dos prismas teóricos e metodológicos por meio dos quais se olha. As questões raciais são representadas e significadas dentro de uma estrutura mais ampla de família, migração e pertencimento. (OLWIG, 2007, p. 16).

Nascida em Guadalupe, residindo em Paris, moradora do Amapá por mais de um ano, mas com fortes laços familiares com a Guiana Francesa, onde sua família de origem guadalupense mora, Samantha possui identidades dentro de redes sociais que a conectam 
a duas ou mais sociedades simultaneamente, assim como Michelle, que também transita e identifica-se com mais de um lugar. Migrações transnacionais superam o "nacionalismo metodológico" (GLICK - SCHILLER, BACH, SZANTON- BLANC, 1992), isto é, o Estado-nação como unidade de análise por excelência, o receptáculo natural e lógico dentro do qual transcorrem processos sociais.

Contudo, é fundamental evitar a homogeneização das experiências de movimentação, para que não se perca a significativa complexidade das vidas em movimento. Conforme adverte Machado (2014), há movimentos, deslocamentos e sentidos particulares a cada experiência, pois as mobilidades dificilmente podem ser imobilizadas em quadros teóricos abrangentes. Mas ao olharmos para determinadas histórias de vida é possível pensar em conexões produtivas para refletir sobre o trânsito humano. Os exemplos de Michelle e Samantha relacionam movimento a transnacionalidade, parentesco e pertencimento, mas isso não permite uma unificação, pois:

as formas de relacionalidade (ou parentesco, para os mais tradicionais) são elas próprias particulares, gerando relações ainda mais específicas com as movimentações. Às teorias gerais escapa o fato de que relações de parentesco fazem movimentações acontecer, sustentam fluxos, constroem justificativas, propõem alternativas de deslocamento. Por outro lado, essas mesmas movimentações colocam em risco as relações que as engendraram. (MACHADO, 2014, p. 38).

Conforme Carsten (2000), o parentesco está nas relações de afeto e lealdade duradoura entre duas ou mais pessoas, por vezes incluindo e por vezes extrapolando os temas da consanguinidade e do matrimônio. A relacionalidade foi fator fundamental na escolha do Amapá, no caso de Samantha, que optou pela região fronteiriça em virtude da facilidade para visitar a família, ao mesmo tempo em que encontrou no Amapá amigos que hoje considera irmãos, inclusive morou na casa deles nos primeiros meses em Macapá. Enquanto Michelle, que também morou na casa de amigos logo que chegou a Macapá, não possui familiares morando tão próximo, contudo, diferente de Samantha, Michelle já possui uma maior relação de pertencimento ao Brasil, pois é naturalizada.

\section{CONSIDERAÇÕES FINAIS}


Michelle e Samantha, caribenhas, nascidas em um DOM (departamento ultramarino), são mulheres que antes mesmo de tornarem-se sujeitos diaspóricos, já carregavam essa dualidade: cidadã francesa/guadalupense; suas trajetórias permitem iluminar a dimensão do "entre lugar", além do mais, para ambas, o Amapá como destino não precedeu a saída do país natal, são migrantes transnacionais. Michelle partiu da Guiana Francesa e Samantha partiu da França, esta última, portanto, caracterizando uma migração norte-sul.

Dessa maneira, a partir das trajetórias de Michele e Samantha, foi possível discutir questões associadas à transnacionalidade, parentesco e pertencimento, sobretudo pelo fato de a mobilidade ser uma marca constitutiva no horizonte de possibilidade dessas mulheres, pois Michelle reside há quase 20 anos em Macapá, mas sempre visita Guadalupe e, apesar do desejo de retornar a morar em sua terra natal, não descarta a possibilidade de ainda morar em outro país; já Samantha residiu um ano no Amapá, retornou a Paris e está pela segunda vez residindo temporariamente em uma cidade amapaense, por ora pretende voltar para Paris quando acabar seu contrato no Brasil, mas também não descarta a possibilidade de morar em outro país.

Apesar de familiarizadas ao atravessamento de fronteiras geográficas e à constante readaptação que a mobilidade implica, Michelle e Samantha encontraram, ao cruzar a fronteira da Amazônia Franco-Brasileira, questões raciais distintas das quais haviam vivenciado até então. As professoras guadalupenses depararam-se com a experiência concreta da relação entre a migração negra e o racismo no Brasil, e de como essa vinculação se manifesta no repertório de ideias que se reproduz sobre população negra no país independentemente da classe social.

\section{REFERÊNCIAS BIBLIOGRÁFICAS}

ANDERSON, Benedict. Comunidades Imaginadas: reflexões sobre a origem e a difusão do nacionalismo. Trad. Denise Bottman. São Paulo: Companhia das Letras, 2008.

BARTH, Fredrik. Grupos étnicos e suas fronteiras. In: POUTGNAT, Philippe, STREIFFFENART, Jocelyne. Teorias da Etnicidade. São Paulo: Ed. UNESP, 2011.

BAUMAN, Zygmunt. Modernidade Líquida. Rio de Janeiro: Zahar, 2001. 
BERnABE, J., CHAMOISEAU, P., CONFIANT R. Éloge de la créolité. Paris: Gallimard, 2015.

BHABHA, Homi. O local da Cultura. Belo Horizonte: UFMG, 2003.

BONINO, Luis. Micromachismos: la violencia invisible en la pareja. Madrid: Paidós, 1998.

BRYCESON, Deborah; VUORELLA, Ulla. The transnational family: new European frontiers and global networkings. New York: Berg, 2002.

CARSTEN, Janet. Cultures of Relatedness: New Approaches to the Study of Kinship. Cambridge University Press, 2000.

CÉSAIRE, Aimé. Discurso sobre a Negritude. Belo Horizonte: Nandyala, 2010.

CUCHE, Denys. A noção de cultura nas ciências sociais. Bauru: Edusc, 2012.

FANON, Frantz. Pele negra, máscaras brancas. Salvador: EDUFBA, 2008.

FIGUEIREDO, Eurídice (org). Construção de identidades pós-coloniais na literatura antilhana. Rio de Janeiro: EdUFF, 1998.

GLICK-SCHILLER, Nina; BASCH, L.; SZANTON-BLANC, C. Towards a definition of transnational perspective on migration: race, class, ethnicity and nationalism reconsidered. New York: New York Academy of Sciences, 1992. Disponível em: <https://nyaspubs.onlinelibrary.wiley.com/toc/17496632/1992/645/1>.

GLISSANT, Edouard. Traité du Tout-monde. Poétique IV. Paris: Gallimard, 1997.

Le Discours antillais. Paris: Éditions du Seuil, 1981.

HALL, Stuart. Pensando a diáspora: reflexões sobre a terra no exterior. In: SOVIK, L. (Org.). Da diáspora: Identity and cultural mediations. Belo Horizonte: UFMG, 2003. p. 25-50.

MACHADO, Igor José Renó. Movimento e parentesco: sobre as especificidades dos deslocamentos. Curitiba: Campos - Revista de Antropologia Social.n.15, 2014, p.27-42. Disponível em: <http://dx.doi.org/10.5380/campos.v15i2.46040>.

MEMMI, Alberto. Retrato do colonizado precedido do retrato do colonizador. Rio de Janeiro: Civilização brasileira, 2007.

OLWIG, Karen Fog. Caribbean Journeys: An Ethnography of Migration and Home in Three Family Network. Duke University Press, 2007. 
QUIJANO, Anibal. Colonialidad del poder y clasificación social. Buenos Aires: Colección Antologías. Consejo Americano de Ciencias Sociales, 2014, p. 285-327. Disponível em: 〈http://biblioteca.clacso.edu.ar/clacso/se/20140506032333/eje1-7.pdf〉.

SCHNAPPER, Dominique. De l'État-nation au monde transnational. Du sens et de l'utilité du concept de diáspora. Revue Européenne des Migrations Internationales, 2001 (17) 2 p. 9-36 Disponível em: <https://www.persee.fr/doc/remi_07650752_2001_num_17_2_1777>.

TÖLÖLYAN, Khachig. Diáspora studies: past, present and promise. IMI Working Paper Series, 2011, n. 55, p.1-14. Disponível em: <https://www.migrationinstitute.org/publications/wp-55-12〉. 